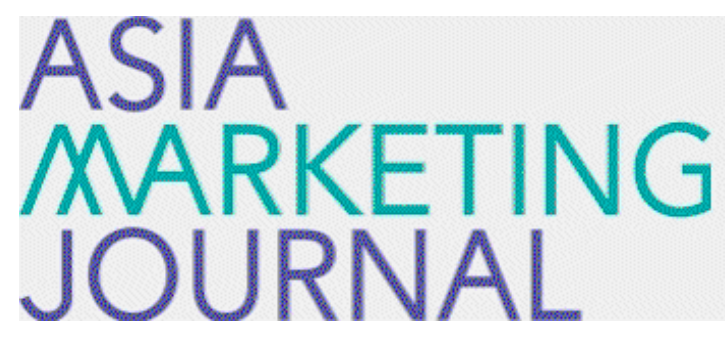

ASIA MARKETING JOURNAL

Volume 22 | Issue 1

Article 1

4-30-2020

\title{
The Detrimental Effect of Customer Demotion on Customer \\ Profitability in Hierarchical Loyalty Programs
}

Woojung Chang

Follow this and additional works at: https://amj.kma.re.kr/journal

Part of the Marketing Commons

\section{Recommended Citation}

Chang, Woojung (2020) "The Detrimental Effect of Customer Demotion on Customer Profitability in Hierarchical Loyalty Programs," Asia Marketing Journal: Vol. 22 : Iss. 1 , Article 1.

Available at: https://doi.org/10.15830/amj.2020.22.1.1

This Article is brought to you for free and open access by Asia Marketing Journal. It has been accepted for inclusion in Asia Marketing Journal by an authorized editor of Asia Marketing Journal. 


\section{The Detrimental Effect of Customer Demotion on Customer Profitability in Hierarchical Loyalty Programs*}

Woojung Chang**

Firms employing hierarchical loyalty programs (HLPs) periodically demote customers from higher to lower status level to divest from unprofitable customers and boost profitability. However, existing literature lacks objective evidence on how customer demotion affects demoted customers' future purchase behaviors and ultimately profitability for the firm. Moreover, customers in the HLP's higher position may respond to customer demotion differently from those in the HLP's lower position. Drawing upon emotions and equity theories, this study quantifies how the profits that customers contribute to the firm change after customer demotion, and compares demoted customers' behavioral reactions from top-tier with those from bottom-tier based on customers' actual behavior data from a major retail bank in South Korea. The findings show that withdrawing customer status actually deteriorates customer profitability, and customers with top-tier status decrease their profitability more dramatically than those with bottom-tier status after demotion. The results contribute to previous literature on customer demotion and relationship marketing, and provide specific guidelines into how firms should design and implement customer demotion in HLPs.

Keywords: customer demotion, hierarchical loyalty programs, customer profitability, emotions theory, equity theory, propensity score matching, difference-in-differences estimator

\section{Introduction}

Hierarchical loyalty programs (HLPs), which award customers differential status (e.g., platinum, gold, and silver members) based on their level of spending with a firm, are common in many service industries (Banik, Gao, and Rabbanee 2019; Bijmolt et al. 2018; Wagner, Hennig-Thurau, and Rudolph 2009). Airlines

\footnotetext{
* This work was supported by the Ministry of Education of the Republic of Korea and the National Research Foundation of Korea (NRF-2017S1A5A8021030).

** Associate Professor of Marketing, Business School, University of Seoul (wchang3@uos.ac.kr)
} 
(e.g., American Airlines and Delta), hotels (e.g., Hilton and Marriott), banking (e.g., UBS, Banco Popular, and Nordea Bank), and even casinos (e.g., Harrah) have utilized HLPs as major marketing tools. The primary logic behind a firm's active adoption of HLPs is that the status that customers attained in such HLPs is a strong motivator of human behavior (Drèze and Nunes 2009; Frank 1985; Henderson, Beck and Palmatier 2011). Not surprisingly, customers with preferred status show attitudinal and behavioral changes toward the firm, including increased attitudinal loyalty, future purchase, and paying premium (Homburg, Droll, and Totzek 2008; Steinhoff and Palmatier 2016; Lacey, Suh, and Morgan 2007).

However, customer status in HLPs is not always elevated from a lower to higher level. When customers fall short of the firm's predefined spending criteria, they often experience customer demotion, the degradation of a customer's elevated status (e.g., from gold to silver or from silver to bronze) (Wagner, Hennig-Thurau, and Rudolph 2009). Firms periodically evaluate customers' spending level with them and degrade customers' status to divest from unprofitable customers and enhance firm profitability (Haenel, Wetzel, and Hammerschmidt 2019; Shin, Sundhir, and Yoon 2012). According to Reed (2005), firms employing HLPs demote thousands of customers every day. However, firms who implement customer demotion to fire unprofitable customers and enhance firm profitability often encounter unexpected backfire effects.

Prior scholars found that demoted customers experience reduction of loyalty program benefits (Wagner, Hennig-Thurau, and Rudolph 2009), negative affect (Wagner, Hennig-Thurau, and Rudolph 2009), perceived unfairness (Banik and Gao 2020), frustration (Banik, Gao, and Rabbanee 2019; Stauss, Schmidt, and Schoeler 2005), and social discomfort (Banik, Gao, and Rabbanee 2019), which ultimately diminish their satisfaction (e.g., Ramaseshan, Stein, and Rabbanee 2016; Ramaseshan and Ouschan 2017), trust and commitment toward the firm (e.g., Ramaseshan, Stein, and Rabbanee 2016; van Berlo, Bloemer, and Blazevic 2014), loyalty intentions (e.g., Banik and Gao 2020; Wagner, Hennig-Thurau, and Rudolph 2009), and enhance their switching intentions (e.g., Banik, Gao, and Rabbanee 2019; Hwang and Kwon 2016). In particular, by indicating the stronger negative impact of customer demotion than the positive effect of status promotion on loyalty intentions, Wagner, Hennig-Thurau, and Rudolph (2009) warned firms of the possibility that customer demotion jeopardizes customer loyalty. Against this backdrop, research into how customers in HLPs respond to customer demotion has been growing in importance (Banik, Gao, and Rabbanee 2019; Bijmolt et al. 2018).

Despite the contributions of prior research on the effects of customer demotion, extant literature has at least two limitations. First, existing research lacks objective evidence on 
the negative effect of customer demotion on customer profitability defined as profits that a customer contributes to a firm. To my best knowledge, all existing research on customer demotion has examined its detrimental effects from customers' attitudinal and perceptual perspective based on experiments and survey from customers. Thus, there is a dearth of objective conclusion about whether reducing customer status in HLPs (i.e., customer demotion) actually deteriorates the customer's purchase behavior and ultimately the firm's profits. Second, despite the possibility that customers who hold different customer status in HLPs may respond differently to customer demotion, differential impact of customer demotion across different status groups of customers has been understudied (Banik and Gao 2020; Ramaseshan and Ouschan 2017). Customers in HLP's toptier position may be more sensitive and respond more negatively to customer demotion than those in bottom-tier position. However, with a few exceptions (e.g., Banik and Gao 2020; Ramaseshan and Ouschan 2017), researchers have mainly focused on studying the simple negative impact of customer demotion and psychological mechanisms underlying the adverse effect. As a discovery of how future behaviors of customers demoted from HLP's top-tier (i.e., top-tier demotion) differ from those of customers degraded from bottom-tier (i.e., bottom-tier demotion) provides crucial insights into how to design and implement effective
HLPs, an exploration of differential reactions to customer demotion is warranted.

To address these research gaps, the objectives of the current study are twofold: (1) to quantify whether customer demotion indeed decreases customer profitability with the firm by comparing customers' actual behavior data from a major retail bank in South Korea before and after customer demotion based on propensity score matching (PSM) method and differencein-differences (DID) estimator, and (2) to gauge how customers in top-tier demotion change their purchase behaviors differently from those in bottom-tier demotion. By doing this, this research extends and contributes to existing literature on customer demotion and the effective use of HLPs. First, this research is among the first to provide a financial evidence on the backfire impact of demoting customers, and alerts managers to imprudent use of customer demotion. Second, this study advances our understanding on customer demotion by showing that all customers in HLPs do not react to customer demotion in the same way. The finding of this paper indicates that customers demoted from top-tier dramatically diminish their spending with the firm, whereas customers demoted from bottom-tier did not cut back their spending substantially after demotion. The results provide specific insights into how a firm should design and execute its policy and criteria on customer demotion differently depending on customers' initial status level. The results help 
mitigate the negative effect of customer demotion and utilize HLPs more effectively.

\section{Theoretical Background and Hypotheses}

\subsection{Emotions Theory and the Effect of Customer Demotion on Customer Profitability}

Traditionally, status has been defined as one's relative position in society (Anderson et al. 2006; Ridgeway and Walker 1995). In this paper, customer status refers to customers' relative place that firms bestow on customers within the HLPs (Drèze and Nunes 2009). Need for status and the need to compare oneself with others are manifest in society (Festinger 1954; Frank 1985; Gilbert, Giesler, and Morris 1995). Accompanying high status and ranking corresponds to a set of exclusive rights and benefits, which often provoke respect, consideration, or envy from other (Ivanic 2015). This deference from others allows customers with high status to enjoy special psychological treatment such as respect and recognition as well as better functional benefits such as exclusive services only available to them (Drèze and Nunes 2009; Wagner, Hennig-Thurau, and Rudolph 2009), leading them to increasing their loyalty, spending more with the firm, and paying premium (de
Wulf, Odekerken-Schröder, and Iacobucci 2001; Homburg, Droll, and Totzek 2008; Lacey, Suh, and Morgan 2007; Steinhoff and Palmatier 2016).

Accordingly, withdrawing preferred customer status and the benefits associated with it (i.e., customer demotion) is expected to deteriorate customer's attitudinal outcomes (e.g., commitment, attitudinal loyalty) and to provoke customer's withdrawal behaviors including pulling back their transactions with the firm or switching (Banik, Gao, and Rabbanee 2019; Hwang and Kwon 2016; Wagner, Hennig-Thurau, and Rudolph 2009). Emotions theory provides theoretical foundations on the negative effect of customer demotion. The basic principle of emotions theory is that emotions evoked by a certain event or problem activate a distinct motivation and behaviors to solve the problem (de Hooge, Zeelenberg, and Breugelmans 2010; Plutchik 1962; Roseman 1984; Wagner, HennigThurau, and Rudolph 2009). Applying emotions theory to the context of customer demotion, a loss of customer status in HLPs is an event or a problem, which elicits negative emotions such as anger and disappointment (Wagner, Hennig-Thurau, and Rudolph 2009), betrayal (Ramaseshan and Ouschan 2017) or frustration (Banik, Gao, and Rabbanee 2019; Stauss, Schmidt, and Schoeler 2005). Customers in the face of customer demotion are likely to provoke withdrawal motivation and behaviors (e.g., switching or decreasing spending level) because 
avoiding or distancing themselves from the negative event may protect themselves.

On the other hand, customers with negative emotions elicited by customer demotion may actively involve in withdrawal behaviors to restore a more equitable state between the firm and themselves. As the firm pulled back its input/efforts for relationship building with the customers through customer demotion, the demoted customers also reduce their level of input/efforts for the relationship through withdrawal behaviors, leading to another equity between the firm and the demoted customers (Adams 1965; Henderson, Beck, and Palmatier 2011: Ramaseshan and Ouschan 2017). By restoring a more equitable state, the demoted customers alleviate the negative emotions and ultimately solve the problem.

In sum, according to emotions theory, demoted customers in HLPs are likely to feel negative emotions and engage in withdrawal behaviors such as switching or reducing purchases to protect themselves by avoiding the negative event or restoring a more equitable state. As a consequence, customer demotion is hypothesized to have a negative impact on customer profitability defined as the profits that a customer made after subtracting the costs of the benefits provided to the customer within the defined period.

Hypothesis 1: Customer demotion has a negative impact on customer profitability.

\subsection{Equity Theory and Differential Effect of Customer Demotion for Top-tier vs. Bottom-tier Customers}

Equity theory posits that people strive for justice in exchange situations (Adams 1963; Finn 2005; Homans 1961; McColl-Kennedy and Sparks 2003). In the process to evaluate equity, they depend on not only the received outcomes but also the investment made (Homans 1961: Wagenheim and Bayón 2007). In the loyalty program context, customers compare the input they contribute to the firm (e.g., purchasing, longer relationship period) to the output they receive from the firm (e.g., loyalty program reward, treatment), and evaluate equity by the ratio of output over input (Adams 1963: Banik and Gao 2020; Ramaseshan and Ouschan 2017).

Equity theory postulates that the negative effect of customer demotion on customer profitability may be greater for top-tier customers than for bottom-tier customers. First, customers who have achieved high status in HLPs tend to view their investment in the relationship with the firm as greater than customers with lower levels of status. Accordingly, top-tier customers regard a higher level of outcomes for themselves as fair. In other words, top-tier customers are likely to have a higher reference point for outcomes and services from the firm. In a similar vein, high-status customers tend to feel more entitled and believe that they 
deserve to receive more and be treated specially (Banik and Gao 2020). In contrast, bottom-tier customers in HLPs are likely to have a lower expectation for output because they have invested less in the relationship with the firm. Since top-tier and bottom-tier customers in HLPs have made different levels of investments in the firm and as a result expect different levels of output from the firm, top-tier customers may perceive a reduction of customer status as more unfair and serious than bottom-tier customers (Adams 1963; Banik and Gao 2020; Ramaseshan and Ouschan 2017). Consequently, customers demoted from top-tier are likely to more actively engage in withdrawal behaviors and dramatically reduce transactions with the firm (Lal and Bell 2003; Wagenheim and Bayón 2007).

Second, top-tier customers may respond more negatively to customer demotion due to their higher dependency on status. Prior scholars have pointed out that high-status customers are more conscious of their high-status and more concerned with maintaining the highstatus (Banik and Gao 2020; Drèze and Nunes 2009; Marr and Thau 2014; Ramaseshan and Ouschan 2017). Since people tend to maximize the importance of domains in which they are successful (Marr and Thau 2014), top-tier customers may view their high status as more important or central component of their self (Drèze and Nunes 2009; Marr and Thau 2014). Thus, withdrawing customer status is expected to be perceived as a greater threat and loss to top-tier customers than to bottom-tier customers. Top-tier customers are more likely to cut back their inputs (i.e., spending level with the firm) than bottom-tier customers to restore an equitable state. Wang et al.'s (2016) finding that while low-status people are more influenced by goal success (e.g., receiving a reward), high-status people are highly affected by goal failure (e.g., not receiving the reward) also supports for greater negative effect of customer demotion on top-tier customers.

Hypothesis 2: The negative effect of customer demotion on customer profitability is greater for top-tier customers than for bottom-tier customers.

\subsection{Control Variables: The Effects of Age, Gender and Duration of Relationship}

Prior research suggests that demographic variables such as age and gender and duration of relationship defined as the duration of the customer-firm relationship influence the associations between customer demotion and customers' emotion, attitude and behaviors toward the firm (Banik, Gao, and Rabbanee 2019; Roschk, Müller, and Gelbrich 2013). Thus, the impacts of age, gender and duration of relationship need to be controlled for. According to Roschk, Müller, and Gelbrich (2013), age 
influences customers' perception on justice. Specifically, as customers get old, they tend to be more concerned with distributive and interactional justice (Roschk, Müller, and Gelbrich 2013). Thus, when being demoted by the firm, old customers might perceive customer demotion as a more unfair situation to break distributive and interactional justice, resulting in higher negative reaction to customer demotion.

With regard to the effect of gender, male customers are found to value their status more positively than female customers (Melnyk and van Osselaer 2012). In line with this argument, Banik, Gao, and Rabbanee (2019) found that male demoted customers feel higher levels of frustration and social discomfort than their female counterparts. In addition to stronger emotion, Grégoire and Fisher (2008) discovered that males tend to use more retaliatory behaviors than females when confronting a violation of fairness norms. Thus, male demoted customers may feel more negative emotion and respond more negatively to customer demotion than female demoted customers due to male's higher dependence on status and greater propensity to retaliate or resolve the inequity driven by customer demotion.

According to equity theory, the duration of relationship may also influence the impact of customer demotion on customer profitability (Banik, Gao, and Rabbanee 2019). As the duration of relationship that customers have transacted with a firm increases, they tend to perceive that they have made much effort in building a relationship with the firm. Thus, customers with longer relationship are more likely to view customer demotion as a violation of equity norms against their cumulative inputs in the relationship. In contrast, customers who have relatively short-period relationship with a firm may not think of customer demotion as contravention of equity norms because they have little vested in the relationship (Adams 1965; Greenberg 1986). Empirical evidence from Banik, Gao, and Rabbanee (2019) that as the duration of relationship increases, the effects of customer demotion on frustration and social discomfort intensify also supports for stronger negative effect of customer demotion for customers with longer relationship. Thus, the impacts of age, gender and the duration of relationship in the customer demotion-customer profitability relationship will be controlled for.

\section{Database}

\subsection{Context}

To objectively quantify the effect of customer demotion on customer profitability, the customer database of a major retail bank in South Korea was analyzed. The South Korea retail banking industry is an appropriate context for examining the effect of customer demotion for several 
reasons. First, retail banks in South Korea have utilized HLPs as major marketing tools since 1994. For example, all four major retail banks in South Korea have introduced HLPs, classified their customers into four to five status levels on the basis of their spending level, and reevaluate their status level every month or every quarter. Thus, by analyzing the database from the South Korea retail banks, researchers are able to vividly observe and provide bank managers with specific insights into how degrading customers affects customers' future purchase behaviors and profitability to the bank.

Second, an exploration of customer demotion in retail banking industry helps generalize its detrimental effect to various contexts. The impact of withdrawing customer status in HLPs has been studied mainly in airline industry (e.g., Banik, Gao, and Rabbanee 2019; Ramaseshan, Stein, and Rabbanee 2016; Ramaseshan and Ouschan 2017; van Berlo, Bloemer, and Blazevic 2014; Wagner, Hennig-Thurau, and Rudolph 2009). Applying customer demotion to HLPs in other industries would increase significance of customer demotion and the reliability of its effect. Lastly, retail banks in South Korea have accumulated rich data related to the changes in customers' status and their purchase behaviors at the individual level for a long time. This accumulated data allows us to analyze longitudinally the changing pattern of customer profitability before and after customer demotion (Liu 2007).

\subsection{Data}

The database for this study contains detailed individual information regarding a customer's loyalty program status level, transactions, customer profitability, and basic demographics, from January 2009 to September 2010. With regard to program status level, the HLP includes four status levels: platinum, gold, silver, and bronze. ${ }^{1)}$ These customers' status levels are reevaluated quarterly based on the transactions during the past quarter. Even though it is possible for customers to be demoted by more than two levels at once (e.g., demotion from platinum to bronze), the sample of this study was limited to customers who underwent the one-level change in customer status in order to control for the magnitude of the status changes. Thus, the sample includes three cases of customer demotion, from platinum to gold (i.e., top-tier demotion), from gold to silver, and from silver to bronze level (i.e., bottom-tier demotion). Although the focus of this study is on the comparison between top-tier and bottom-tier demotion, customer demotion from gold to silver status level (i.e., middle-tier demotion) will be also analyzed and reported for completeness.

Information on customer transactions includes

1) For anonymity, the names of the status levels in the loyalty program are changed. 
the average balance of checking, savings, and money market accounts and the average amount of personal loan including home mortgage during the past three months. The average balances of the above transactions during the past three months are utilized as mechanisms to select customers who are demoted. Regarding customer profitability, the database provides information on profits at the individual level by subtracting the costs to serve the customer from the revenue that the customer contributed to the bank during the past quarter. Information on basic demographics such as age and gender and the duration of the customer relationship with the bank is also included in the database.

In a nutshell, as the bank's database presents quarterly data on a customer's transactions and his/her profitability, the database includes longitudinal data with seven data points from the first quarter of 2009 to the third quarter of 2010 (e.g., see Figure 1). A random sample of 4,000 customers was first obtained from the customer base, which is composed of 1,000 customers at each status level (i.e., platinum, gold, silver, and bronze) as of January 2009. Among the customers, all customers who had experienced one-level customer demotion after the second quarter of 2009 were found and analyzed to investigate the effect of customer demotion.

\section{Analytical Procedures}

The database provides longitudinal data on customer profitability with seven quarterly data points from the first quarter of 2009 to the third quarter of 2010. As behavioral changes of customers demoted after the second quarter of 2009 were analyzed, data on customer profitability in the first and second quarter of 2009 represent customers' profitability patterns before experiencing customer demotion, while those from the third quarter of 2009 to the third quarter of 2010 show customers' profitability pattern after customer demotion (see Figure 1). This enables us to analyze and compare a customer's profitability before and after demotion.

From a methodological point of view, researchers need to compare changes in customer profitability before and after customer demotion as well as to contrast changes in customer profitability of demoted customers with those of undemoted customers in order to prove the potential backfire effect of customer demotion. Thus, from analytical perspective, customer demotion can be viewed as a "treatment" that some customers receive (Wagenheim and Bayón 2007). To explore the "treatment effect" on customer profitability, the demoted customers (i.e., treatment group) need to be matched to customers in the HLP who showed very similar purchase behaviors before the event of customer demotion but were not degraded by the bank after the second 
quarter of 2009 (i.e., control group). The process to match and create a control group will be based on propensity score matching (PSM) technique. Then, the difference in customer profitability of the two groups of customers (i.e., demoted treatment group vs. undemoted control group) will be compared by employing difference-in-differences (DID) estimator. These series of analytical procedures have been well accepted in the analysis of treatment effects in a non-experimental setting (Garnefeld et al. 2013; Kumar et al. 2016; Wagenheim and Bayón 2007).

\subsection{Propensity Score Matching}

The overall analytical procedures of this study are similar to those of experiments. Unlike randomized experiments, however, the analysis of treatment effects in a non-experimental setting such as in this paper has been a concern in the econometric literature (Heckman, Ichimura, and Todd 1997; Rosenbaum and Rubin 1984). The PSM method was introduced by Rosenbaum and Rubin (1983) in an attempt to solve this lack of randomization by artificially creating a control group in which each treatment recipient is matched to a similar non-recipient. Because the similar control group is expected to show similar behavioral patterns with a treatment group, the difference in customer future behavior between control and treatment groups can be attributed to the treatment.
The PSM method typically utilizes three stages. In the first stage, a logistic or probit regression is run to obtain propensity scores for all treatment recipients and non-recipients. The propensity score is the probability of the event occurring, in this case, the likelihood that a customer experiences customer demotion. Second, each customer who underwent customer demotion is matched to a customer who did not, based on the closest propensity scores which have been obtained from the first stage. Finally, the quality of the matching is evaluated by computing how much the difference between treatment and control groups is reduced after matching based on the percentage reduction in bias (PRB). The purpose of the three stages of PSM method is simply for creating a matching sample composed of a treatment group that underwent customer demotion by the bank's HLP and a similar control group that did not.

\subsection{Difference-in-Differences Estimator}

To test the treatment effect of customer demotion, DID estimations were conducted based on the matching samples. DID is a nonexperimental technique to measure the effect of a treatment (Dallmann 2001). The DID estimate is to examine the effect of a treatment by comparing the before-and-after difference of the treatment group with the before-and-after difference of the control group as shown in Equation 1 (Imbens and 
Wooldridge 2008).

(1) $\hat{\beta}=\left(\bar{y}_{B, 2}-\bar{y}_{B, 1}\right)-\left(\bar{y}_{A, 2}-\bar{y}_{A, 1}\right)$

where $\hat{\beta}$ is the estimated treatment effect, $\left(\bar{y}_{B, 2}-\bar{y}_{B, 1}\right)$ is the before-and-after difference of the treatment group, and $\left(\bar{y}_{A, 2}-\bar{y}_{A, 1}\right)$ is the before-and-after difference of the control group. This estimate removes the difference between a treatment and a control group in the initial stage as well as biases from comparisons over time in the treatment group that could be the result of trends (Imbens and Wooldridge 2008). The combination of PSM with a DID technique has been found to be less sensitive to bias than all other known methods for evaluating treatment effects in a nonexperimental setting where a randomization process to control for unobserved variables is not applied (Heckman, Ichimura, and Todd 1997).

(2) $\Delta y_{i}=\alpha+\beta D_{i}+\varepsilon_{i}$

In the simplest setting where there are two time periods (i.e., before and after), the beforeand-after difference of the outcome variable (i.e., $\Delta y_{i}$ ) is determined as the effect of treatment $\mathrm{D}$ where $\mathrm{D}=1$ for treatment case and $\mathrm{D}=0$ for control case.

(3) $y_{i t}=\beta x_{i t}+\mu_{i}+\varepsilon_{i t}$
As shown in Equation 3, Equation 2 can be extended to a panel setting containing multiple observations over multiple time periods for the same individuals like in this paper (Wagenheim and Bayón 2007). $y_{i t}$ is the dependent variable, i.e., the difference-in-differences in the customer profitability, and is written as a function of the treatment effect $\beta$, an individual-specific, time-invariant disturbance $\mu_{i}$, and classical disturbance $\varepsilon_{i t}$. Equation 3 was analyzed based on the random-effects model.

\section{Results}

\subsection{Matching Results}

Before specifically testing the hypotheses, the results and the quality of matching are described. Following the three stages of PSM technique, several logistic regressions for the customers of the same status group were first run to obtain the propensity scores and match the treatment receivers only with non-treatment receivers of the same status group (Heckman, Ichimura, and Todd 1997; Wangenheim and Bayón 2007). While the dependent variable of the logistic regressions is whether or not a customer experiences customer demotion, independent variables include the average balances of checking, savings, money market 
accounts, and personal loans during the past three months as the demotion selection mechanism specifies. For example, a logistic regression was employed based on only customers with platinum status during the second quarter of 2009. Among the customers, some experienced one level of customer demotion from platinum to gold just after the second quarter of 2009, whereas others maintained their platinum status. The logistic regression based on the sample provided us with propensity scores of treatment and non-treatment receivers in the platinum level. In this way, in total three logistic regressions were conducted for three types of customer demotion (i.e., demotion from platinum to gold, from gold to silver, and from silver to bronze).

Then, in the second stage of PSM technique, treatment receivers who were degraded after the second quarter of 2009 were matched to similar non-treatment receivers who maintained customer status level using the propensity scores from the logistic regressions. Specifically, a caliper matching technique was applied in which the treatment-recipient was matched with the non-recipient closest to its propensity score with a tolerance zone for the difference in the propensity score between matches and non-matches (Cochran and Rubin 1973). After applying caliper matching with the tolerance zones, 31 demoted from platinum to gold, 74 demoted from gold to silver, and 81 demoted from silver to bronze were matched, which results in total 186 demotion cases. Since the 186 demotion cases have their respective matched

〈Table 1〉 Group Means Before and After Matching and Percentage Reduction in Bias (PRB)

\begin{tabular}{cccccc}
\hline \multicolumn{2}{c}{ Before Matching } & & \multicolumn{3}{c}{ After Matching } \\
\hline Control & Demotion & From Platinum to Gold & Control & Demotion & PRB \\
\hline 914.53 & 477.82 & Ave. balance of checking & 144.97 & 188.90 & $89.94 \%$ \\
7257.84 & 1336.45 & Ave. balance of savings & 1569.03 & 1817.42 & $95.81 \%$ \\
2142.17 & 669.74 & Ave. balance of money market accounts & 713.03 & 720.45 & $99.50 \%$ \\
1020.05 & 618.37 & Ave. amount of personal loans & 1135.81 & 833.68 & $24.78 \%$ \\
\hline Control & Demotion & From Gold to Silver & Control & Demotion & PRB \\
\hline 237.59 & 398.75 & Ave. balance of checking & 445.22 & 388.05 & $64.53 \%$ \\
873.11 & 635.42 & Ave. balance of savings & 593.24 & 624.05 & $87.04 \%$ \\
548.14 & 371.30 & Ave. balance of money market accounts & 361.14 & 354.54 & $96.27 \%$ \\
996.76 & 306.40 & Ave. amount of personal loans & 205.36 & 343.28 & $80.02 \%$ \\
\hline Control & Demotion & From Silver to Bronze & Control & Demotion & PRB \\
\hline 181.42 & 241.19 & Ave. balance of checking & 270.26 & 236.78 & $43.98 \%$ \\
445.07 & 231.08 & Ave. balance of savings & 223.95 & 226.91 & $98.62 \%$ \\
357.97 & 148.00 & Ave. balance of money market accounts & 152.81 & 151.65 & $99.45 \%$ \\
497.48 & 219.95 & Ave. amount of personal loans & 183.81 & 225.38 & $85.02 \%$ \\
\hline
\end{tabular}


cases, the total matched sample is composed of 372 customers.

Finally, the quality of the matching was assessed by computing the percentage reduction in bias (PRB), following the formula in Appendix (Wangenheim and Bayón 2007). PRB represents how much the difference between treatment and control groups is reduced after PSM. Table 1 displays the PRB for customer demotion. The results reveal that treatment groups for three pairs of customer demotion seem to be more similar to their respective control groups after caliper matching, and the differences between them substantially decreased in terms of the average balances of checking, savings, and money market accounts. Although some differences between the control and treatment groups still remain even after matching due to relatively small size of customer random sample (i.e., 1000 for each status group), the results of the PRB support that the series of matching procedures substantially decreased the initial differences between the control and treatment groups and enabled us to compare the two groups.

\subsection{Overall Effect of Customer Demotion}

The fundamental question underlying this research is whether a treatment effect of customer demotion on customer profitability can be observed objectively. A first impression can be obtained from Figure 1 which displays the mean profitability of the treatment group who experienced customer demotion as well as its respective control group over time. As shown in Figure 1, the treatment groups who were demoted and the control groups exhibited

〈Figure 1〉 Customer Profitability Comparison between Demoted and Control Groups

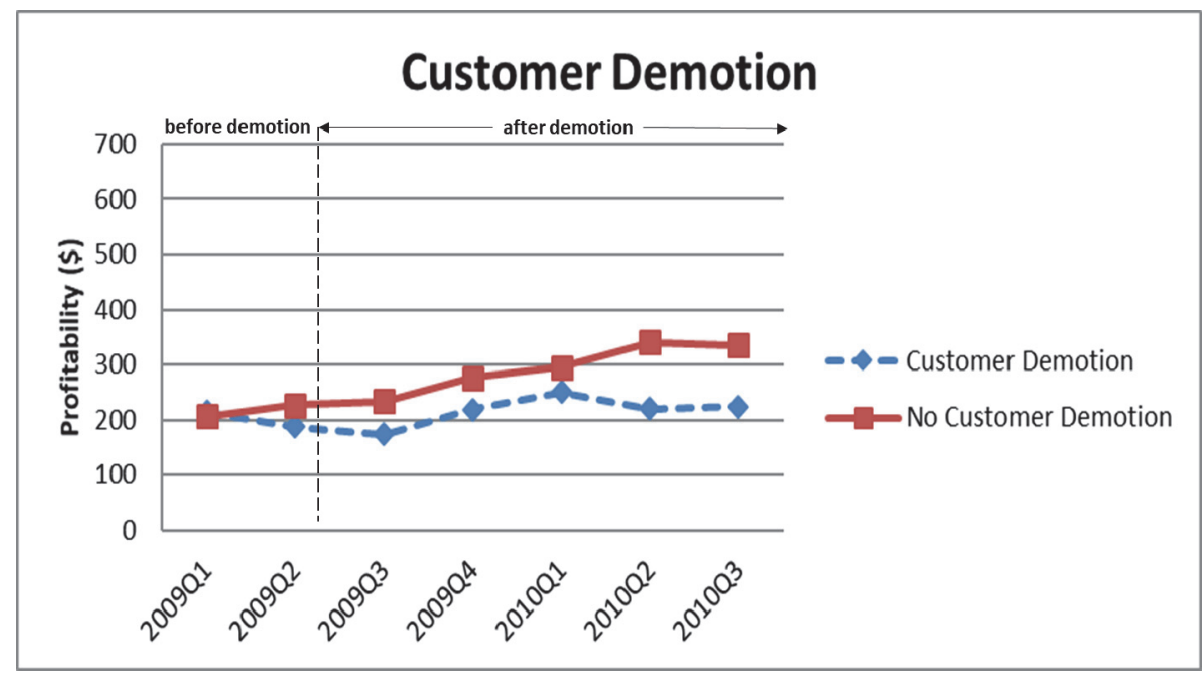

The Detrimental Effect of Customer Demotion on Customer Profitability in Hierarchical Loyalty Programs 13 
similar mean customer profitability before the treatments occur (i.e., in the first and the second quarters of 2009) as a result of the matching procedures. However, after the treatment reception (i.e., just after the second quarter of 2009), both groups showed differences in mean customer profitability. Degraded customers contributed less profit to the bank than a control group.

To specifically test the Hypothesis 1, Equation 3 was run based on the combined sample which merged three pairs of customer demotion matching samples (i.e., demotion from platinum to gold, demotion from gold to silver, and demotion from silver to bronze). In the equation, a customer's age, gender, and duration of relationship with the firm were included as covariates to control for the bias that had not been removed by the matching procedure. The results based on the combined sample were seen in Table 2.

As Table 2 demonstrates, overall customer demotion had a negative effect on customer profitability $(\beta=-81.24, p<.01)$, supporting Hypothesis 1. Specifically, customers who were degraded contributed $\$ 81.24$ less during the three months than those who were not been demoted. A few significant results of covariates were also found. Males customers and olderaged customers indicated greater impact on the difference-in-differences for customer profitability. However, contrary to our expectation, the duration of the relationship with the firm did not influence the difference in customer profitability. Prior research including Banik, Gao, and Rabbanee (2019) showed that as the duration of the relationship increases, demoted customers responded more negatively to customer demotion in the airline HLP context. The contrary result in this paper may be explained by bank customers' relatively high switching costs. Customers with longer history with a bank in the bank industry tend to perceive it as more burdensome to switch their primary bank to other bank than those in the airline industry who switch to other airline because

〈Table 2〉 Effects of Customer Demotion on a Customer's Profitability

\begin{tabular}{lcc}
\hline \multicolumn{1}{c}{ Independent Variables } & Sample Size & $\begin{array}{c}\text { Dependent Variable: } \\
\text { Difference-in-Differences for a } \\
\text { Customer's Profitability }\end{array}$ \\
\hline Customer Demotion & 372 & $-81.24(22.10)^{* * *}$ \\
Age & & $2.73(1.01)^{* *}$ \\
Gender $(1=$ female $)$ & $-67.62(22.56)^{* *}$ \\
Duration of the relationship & $1.35(1.89)$ \\
Constant & $-63.37(76.19)$ \\
\hline$* * p<.01$. &
\end{tabular}


bank customers with longer history need to close all accounts in the prior bank and open various accounts in the new bank and re-set up automatic transfers, etc. Due to this high level of switching costs perceived by bank customers with longer history, customers in this research may not actually decrease their future behavior toward the bank even if the duration of the relationship increases.

\subsection{Difference in the Effect According to Customer Status}

Figure 2 demonstrates the differences in customer profitability between a treatment group and a control group for three pairs of customer demotion, demotion from platinum to gold (i.e., top-tier demotion), demotion from gold to silver, and finally demotion from silver to bronze status level (i.e., bottom-tier demotion). Overall, these figures confirmed the finding of the combined sample such that customers who experienced customer demotion contributed profits less than those who did not.

However, the patterns of mean customer profitability significantly vary according to a customer's status level. The most detrimental effect of customer demotion was found among the top-tier demoted customers degraded from platinum to gold status level. In this case, the difference of mean customer profitability between treatment and non-treatment recipients was broadened over time. Customers who maintain their platinum status in HLPs are perceived to be a segment which can dramatically increase profitability for the firm. However, after losing their preferred platinum status, customers who used to be in the platinum status level significantly decreased their contribution toward bank profits. In the demotion case from gold to silver, a similar finding that demoted customer made less profits for the bank than undemoted counterparts after undergoing customer demotion was found. However, the difference in customer profitability between demoted and undemoted control groups was much smaller than that for top-tier demotion. Notably, customers in the bank's relatively lower status level (i.e., silver status) did not reveal a big change in usage pattern after being demoted to a bronze status level, and made a similar level of profits to what customers who remained in the silver level contributed to the bank.

To statistically test the differential effects of customer demotion, equation 3 was analyzed for three pairs of customer demotion samples, respectively. As Table 3 indicates, the findings revealed the negative impact of customer demotion only for the top-tier demotion sample $(\beta=-280.85, p<.01)$. Customers in the sample demoted from gold to silver $(\beta=$ -53.63, $p<.1$ ) and customers who were degraded from silver to bronze did not show the negative effects of customer demotion ( $\beta=$ $-25.50, p>.1)$ at the .05 level. In other words, while customers in top-tier demotion (vs. top- 
〈Figure 2〉 Customer Profitability Comparison between Demoted and Control Groups on a Status Level
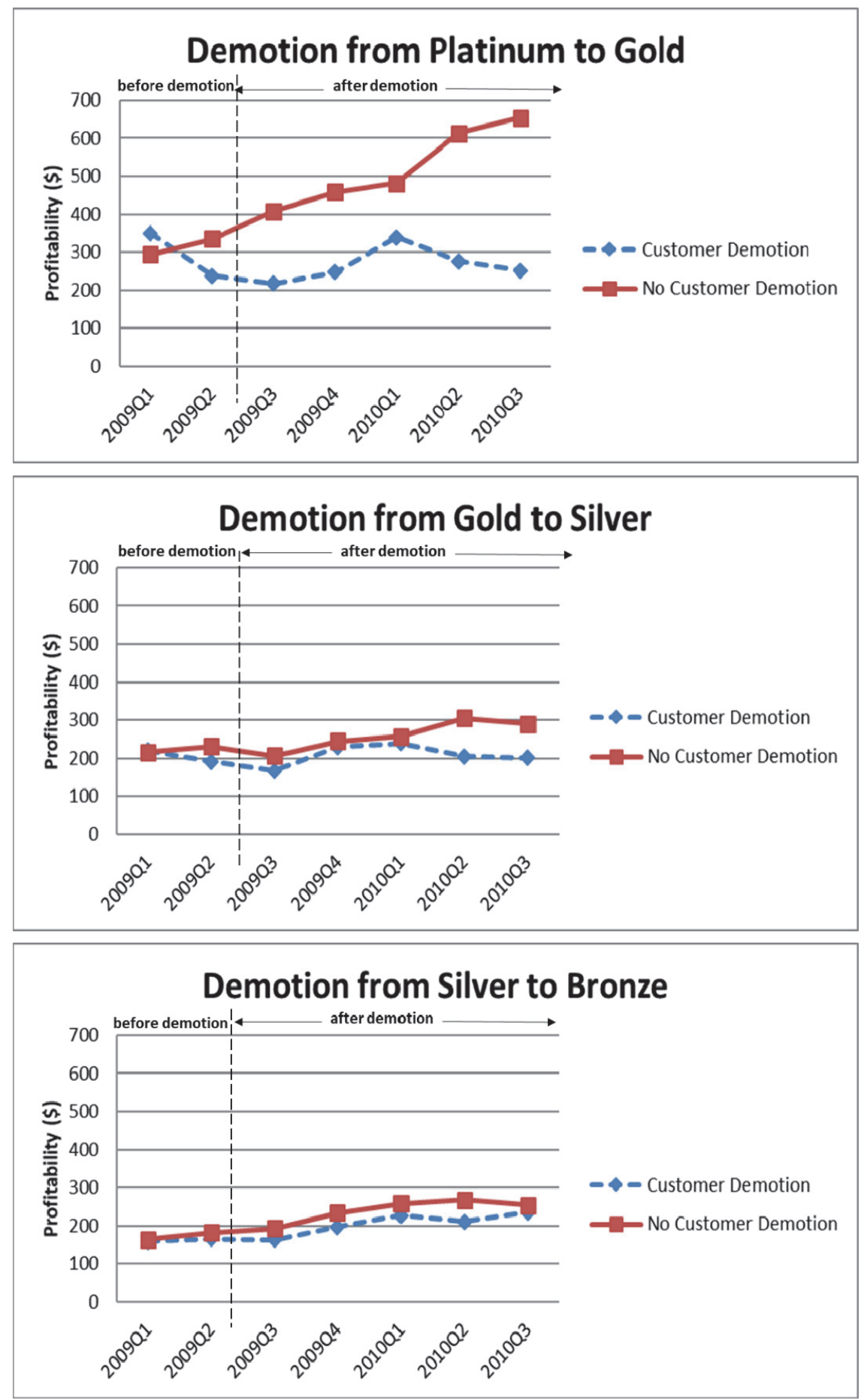
tier's undemoted control group) contributed $\$ 280.85$ less to the bank's profits on a quarterly basis, customers in bottom-tier demotion contributed only \$25.50 less than bottom-tier's undemoted control group. Thus, these results lend support for Hypothesis 2 that customers in top-tier demotion are more sensitive to customer demotion than those in bottom-tier demotion.

\section{Discussion}

\subsection{Theoretical Implications}

The findings of this study contribute to the loyalty program research and relationship marketing literature. First, the current study is among the first to quantify and provide a

〈Table 3〉 Effects of Customer Demotion for Different Status Groups

\begin{tabular}{|c|c|c|}
\hline Independent Variables & Sample Size & $\begin{array}{c}\text { Dependent Variable: } \\
\text { Difference-in-Differences for a } \\
\text { Customer's Profitability }\end{array}$ \\
\hline Customer Demotion From Platinum to Gold & 62 & \\
\hline Customer Demotion & & $-280.85(76.17)^{* * *}$ \\
\hline Age & & $3.17(3.10)$ \\
\hline Gender $(1=$ female $)$ & & $-112.00(77.79)$ \\
\hline Duration of the relationship & & $4.94(6.00)$ \\
\hline Constant & & $14.08(227.18)$ \\
\hline Customer Demotion From Gold to Silver & 148 & \\
\hline Customer Demotion & & $-53.63(31.45)^{*}$ \\
\hline Age & & $3.62(1.45)^{* *}$ \\
\hline Gender $(1=$ female $)$ & & $-39.55(33.75)$ \\
\hline Duration of the relationship & & $2.35(2.79)$ \\
\hline Constant & & $-193.24(114.39)^{*}$ \\
\hline Customer Demotion From Silver to Bronze & 162 & \\
\hline Customer Demotion & & $-25.50(29.11)$ \\
\hline Age & & $1.47(1.39)$ \\
\hline Gender $(1=$ female $)$ & & $-79.43(29.38)^{* * *}$ \\
\hline Duration of the relationship & & $.05(2.58)$ \\
\hline Constant & & $29.51(104.02)$ \\
\hline
\end{tabular}


financial evidence for the adverse impact of customer demotion. While customers in HLPs have frequently experienced reductions in their status, marketing academics have just recently begun investigating the impact of customer demotion (Banik and Gao 2020; Ramaseshan and Ouschan 2017). Thus, existing research on customer demotion has focused on identifying a simple negative effect of customer demotion on demoted customers' satisfaction, trust, commitment, and attitudinal loyalty as well as psychological mechanisms underlying the detrimental impact by using customers' perception measures. Despite their contributions, however, managers to design and employ a firm's HLP really want to know whether withdrawing customer status deteriorates the demoted customer's actual future purchase behavior and ultimately profits that the demoted customer makes for the firm. By calculating how much customer profits degraded customers decreased compared with their counterparts who had similar purchase behaviors but did not experience customer demotion, this study provides a strong objective evidence for the results of previous research on customer demotion.

Second, the current research provides new insights into how individual customers respond to customer demotion differently. The findings indicate that customers with higher status level react more strongly to customer demotion. This result is consistent with equity theory that customers' perception on equity depends on not only inputs but also outcomes. Customers with higher status level tend to perceive that they have invested higher inputs in the relationship with the firm than those with lower status level. Thus, customers with higher status level have higher expectations from the firm and perceive the higher outcomes as fair. As a result, when confronting customer demotion, customers with higher status level experience higher unfairness, loss, and threat, resulting in a more detrimental reaction to customer demotion. This differential effect of customer demotion across different customer groups confirms equity theory's fundamental principle that the ratio of outputs over inputs (not just outputs) determines people's perception of equity.

Finally, the results of this paper ratify the relationship marketing norms in the HLP context. The backfire and differential effects of customer demotion found in this study validate the significance of keeping reciprocity norms between two exchange partners to maintain the relationship, which relationship marketing scholars have emphasized consistently (Wang et al. 2016). Withdrawing customer status from customers who believe them to have invested in the relationship with the firm and to deserve to receive a return from the firm is perceived to break reciprocity norms, and thus leads them to reduce their transactions with the firm. Furthermore, relationship marketing literature highlights differential treatment of different customer groups (Homburg, Droll, and 
Totzek 2008; Lacey, Suh, and Morgan 2007; Zeithaml, Rust, and Lemon 2001). Customers' differential reactions to customer demotion corroborate the need for firms to differentiate customers based on their initial status level and treat them differently when executing customer demotion.

\subsection{Managerial Implications}

The findings of this study provide specific guidelines on how firms should implement customer demotion in HLPs. First, firms which employ HLPs as their major marketing tools are advised to be wary of executing customer demotion without carefully considering its adverse effect on customer profitability. The present paper corroborates that degrading customers in HLPs leads them to withdraw their actual purchases and ultimately profits to the firm beyond the negative effect on customer's attitudinal loyalty that previous studies found. Therefore, demoting customers periodically may not help improve firms' profitability even though firms implement customer demotion in an effort to divest from unprofitable customers and enhance firms' profitability (Haenel, Wetzel, and Hammerschmidt 2019; Shin, Sundhir, and Yoon 2012). Given the detrimental impact of customer demotion on demoted customers' profitability, firms need to pay more attention to identifying unprofitable customers who should be divested and degrading them instead of automatically applying firms' predefined demotion criteria.

Second, managers in charge of HLPs should set more generous standard of customer demotion for high-status customers. Given that high status customers react more strongly to customer demotion, managers need to be particularly careful to degrade high-status customers. A large proportion of sales and profits are likely to be generated by high-status customer group (Drèze and Nunes 2009; Ramaseshan and Ouschan 2017). A firm may not want to lose high-status customers who temporarily missed its specified spending criteria by demoting and driving them to pulling back their transactions with the firm. Thus, firms are advised to consider applying more generous standard of customer demotion for their high-status customers. For example, firms could offer high-status customers grace period when high-status customers can remain their status even though they fall short of the required spending level that firms predefine. If high-status customers are kept informed of that they are decreasing their spending level, they may attempt to return to their previous spending level with the firms in the grace period. Another way is that companies can provide only high-status customers with rollover promotion which allows customers to carry forward extra elite-qualifying points that are not needed to reach a status level to the next year. Delta Air lines and Marriott Hotel launched rollover programs and provided 
the benefits to elite-status customers in an attempt to keep customers staying (Yamanouchi 2009). This rollover program could avoid that high-status customers who have long invested in the relationship with companies lose their preferred status only based on the transactions of the previous year.

Lastly, managers of HLPs should strive for customer prioritization (Homburg, Droll, and Totzek 2008). The results indicate that customers with low level status do not decrease their profitability when they are degraded. Thus, firms may benefit from demoting low-status unprofitable customers and allocating the resources assigned to the low-status customers to high-status customers. Consequently, firms can reduce marketing costs required to give benefits to low-status customers without dramatic decrease of profits, and simultaneously enhance profits by prioritizing customers with high status.

\subsection{Limitations and Further Research}

Although this study provides new insights into behavioral and monetary effect of customer demotion, further research is needed to gain additional insights into this issue. First, future researchers need to investigate the effect of customer demotion on customer profitability with a larger database and better matching sample. Despite the contribution to quantify the adverse impact of customer demotion with a firm's actual customer database, the random sample of this paper was relatively small (i.e., 1000 customers for each status level), which therefore resulted in imperfect matching samples. The relatively imperfect matching samples make it difficult to correctly assess whether the difference in profitability between demoted customers and undemoted customers after customer demotion is caused by the pattern that demoted customers constantly decrease their business with the bank even before customer demotion or whether the difference is attributed by the demotion. Therefore, future researcher can verify and generalize the negative effect of customer demotion on demoted customers' future purchase behaviors by analyzing better matched samples from large HLP databases in various industries.

Second, future researchers need to explore the effect of customer demotion that structural changes in HLPs cause. The current paper examines how customers respond to demotion under static hierarchical structure. However, structures of HLPs are not always fixed. In 2010, Delta Air Lines added a "diamond" tier to its existing three-tier HLP (Stellin 2009). As a result of the addition of diamond tier above the previous top status (i.e., platinum), platinum customers are unintentionally demoted from top to the second status even though they have satisfied the predefined spending level of the status. In addition, AirTran lowered its threshold to reach elite status in its own frequent-flier program, which makes customers 
who fall short of the previous threshold for elite status promoted (Yamanouchi 2009). As such, structural changes in HLPs may accompany unintentional changes in customer perceptions of status, and thus, the impact of customer demotion (Dréze and Nunes 2009). Therefore, future researchers could gain new insights by investigating how customer demotion that is caused by structural changes in HLPs affects customers' behavioral patterns.

Third, the current study did not explore the specific actions on how to mitigate the negative influence of customer demotion. However, the findings of this paper imply that firms could gain financial benefits by effectively alleviating the strong negative effect of customer demotion for top-tier customers. As mentioned before, investigating how a rollover program or the grace period can come into play in mitigating the negative effect of customer demotion will provide managers with new insights into the effective implementation of HLPs. The results will extend the finding of Wagner, HennigThurau, and Rudolph (2009) that reminding customers proactively of both their spending decline and the formal requirements to maintain the elevated status could alleviate the pain of customer demotion.

Finally, future research needs to study customers' emotional protest behaviors as well as withdrawal behaviors after customer demotion. Previous literature indicates that in face of service failure, customers not only withdraw their relationship with firms but also protest their negative emotion (Bechwati and Morrin 2003; Grégoire and Fisher 2008; Grégoire, Tripp, and Legoux 2009). While this paper focuses on customers' withdrawal behaviors after customer demotion, future researchers could obtain additional insights by examining customers' protest behaviors such as retaliating or spreading negative word-of-mouth.

〈Received January 5. 2020〉

$\langle$ Accepted April 13. 2020〉

\section{References}

Adams, J. Stacey (1963), “Toward an Understanding of Inequity," Journal of Abnormal and Social Psychology, 67(5), 422-36.

Adams, J. Stacey (1965), "Inequity in Social Exchange," in Advances in Experimental Social Psychology, Vol.2, Leonard Berkowitz ed. New York: Academic Press, 267-99. Anderson, Cameron, Sanjay Srivastava, Jennifer S. Beer, Sandra E. Spataro, and Jennifer A. Chatman (2006), "Knowing Your Place: Self-Perceptions of Status in Face-to-Face Groups," Journal of Personality and Social Psychology, 91, 1094-1110.

Banik, Shanta and Yongqiang Gao (2020), "Status Demotion in Loyalty Programmes: The Role of Perceived Unfairness," Service 
Industries Journal, 40(3-4), 315-36.

Banik, Shanta, Yongqiang Gao, and Fazlul K. Rabbanee (2019), "Status Demotion in Hierarchical Loyalty Programs and Its Effects on Switching: Identifying Mediators and Moderators in the Chinese Context," Journal of Business Research, 96, 125-34. Bechwati, Nada Nasr and Maureen Morrin (2003), "Outraged Consumers: Getting Even at the Expense of Getting a Good Deal," Journal of Consumer Psychology, 13(4), 440-53.

Bijmolt, Tammo H. A., Manfred Krafft, Javier F. Sese, and Vijay Viswanathan (2018), "Multi-tier Loyalty Programs to Stimulate Customer Engagement," in Palmatier, R. W., Kumar, V. and Harmeling, C. M. (Eds.), Customer Engagement Marketing, Palgrave Macmillan, Cham, Switzerland, 119-39.

Cochran, W. and Donald J. Rubin (1973), "Controlling Bias in Observational Studies: A Review," Sankhya, 35(4), 417-46. Dallmann, Katharina M. (2001), "Targeting Women in German and Japanese Magazine Advertising: A Difference-in-Differences Approach," European Journal of Marketing, 35(11/12), 1320-39.

de Hooge, Ilona E., Marcel Zeelenberg, and Seger M. Breugelmans (2010), "Restore and Product Motivations Following Shame," Cognition and Emotion, 24(1), 111-27. de Wulf, Kristof, Gaby Odekerken-Schröder, and Dawn Iacobucci (2001), "Investments in Consumer Relationships: A Cross-Country and Cross-Industry Exploration," Journal of Marketing, 65(October), 33-50.

Drèze, Xavier and Joseph C. Nunes (2009), "Feeling Superior: The Impact of Loyalty Program Structure on Consumers' Perceptions of Status," Journal of Consumer Research, 35(April), 890-905.

Festinger, Leon (1954), "A Theory of Social Comparison Processes," Human Relations, 7(2), 117-40.

Finn, Adam (2005), "Reassessing the Foundations of Customer Delight," Journal of Service Research, 8(2), 103-16.

Frank, Robert (1985), Choosing the Right Pond: Human Behavior and the Quest for Status, New York: Oxford University Press.

Garnefeld, Ina, Andreas Eggert, Sabrina V. Helm, and Stephen S. Tax (2013), "Growing Existing Customers' Revenue Streams Through Customer Referral Programs," Journal of Marketing, 77(4), 17-32.

Gilbert, Daniel T., R. Brian Giesler, and Kathryn A. Morris (1995), "When Comparisons Arise," Journal of Personality and Social Psychology, 69(2), 227-36.

Greenberg, Jerald (1986), "Determinants of Perceived Fairness of Performance Evaluations," Journal of Applied Psychology, 71(May), $340-42$.

Grégoire, Yany and Robert J. Fisher (2008), 
"Customers Betrayal and Retaliation: When Your Best Customers Become Your Worst Enemies," Journal of the Academy of Marketing Science, 36, 247-61.

Grégoire, Yany, Thomas M. Tripp, and Renaud Legoux (2009), "When Customer Love Turns into Lasting Hate: The Effects of Relationship Strength and Time on Customer Revenge and Avoidance," Journal of Marketing, 73(November), 18-32.

Haenel, Christina M., Hauke A. Wetzel, and Maik Hammerschmidt (2019), "The Perils of Service Contract Divestment: When and Why Customers Seek Revenge and How It Can Be Attenuated," Journal of Service Research, 22(3), 301-22.

Heckman, James, Hidehiko Ichimura, and Petra E. Todd (1997), "Matching as an Econometric Evaluation Estimator: Evidence from Evaluating a Job Training Programme," Review of Economic Studies, 64(4), 60554.

Henderson, Conor M., Joshua T. Beck, and Robert W. Palmatier (2011), "Review of the Theoretical Underpinnings of Loyalty Programs," Journal of Consumer Psychology, 21(3), 256-76.

Homans, G. C. (1961), Social Behavior: Its Elementary Forms. New York: Harcourt, Brace \& World.

Homburg, Christian, Mathias Droll, and Dirk Totzek (2008), "Customer Prioritization: Does It Pay Off, and How Should It Be
Implemented?" Journal of Marketing, 72 (September), 110-30.

Hwang, Insuk and Hyukjin Kwon (2016), "Effects of Demotion in Loyalty Programs on Brand-Switching Intentions," Service Business, 10(3), 489-505.

Imbens, Guido and Jeffrey M. Wooldridge (2008), Recent Developments in the Econometrics of Program Evaluation. Cambridge: National Bureau of Economic Research.

Ivanic, Aarti S. (2015), "Status has Its Privileges: The Psychological Benefit of Status-Reinforcing Behaviors," Psychology \& Marketing, 32(7), 697-708.

Kumar, Ashish, Ram Bezawada, Rishika Rishika, Ramkumar Janakiraman, and P.K. Kannan (2016), "From Social to Sale: The Effects of Firm-Generated Content in Social Media on Customer Behavior," Journal of Marketing, 80(1), 7-25.

Lacey, Russell, Jaebeom Suh, and Robert M. Morgan (2007), "Differential Effects of Preferential Treatment Levels on Relational Outcomes," Journal of Service Research, 9 (3), 241-56.

Lal, Rajiv and David E. Bell (2003), "The Impact of Frequent Shopper Programs in Grocery Retailing," Quantitative Marketing and Economics, 1(2), 179-202.

Liu, Yuping (2007), “The Long-Term Impact of Loyalty Programs on Consumer Purchase Behavior and Loyalty," Journal of Marketing, 71(October), 19-35. 
Marr, Jennifer C. and Stefan Thau (2014), "Falling From Great (and Not-So-Great) Heights: How Initial Status Position Influences Performance After Status Loss," Academy of Management Journal, 57(1), 233-48.

McColl-Kennedy, Janet and Beverley A. Sparks (2003), "Application of Fairness Theory to Service Failures and Service Recovery," Journal of Service Research, 5(3), 251-66.

Melnyk, Valentyna and Stijin MJ van Osselaer (2012), "Make Me Special: Gender Differences in Consumers' Responses to Loyalty Programs," Marketing Letters, 23(3), 545-59.

Plutchik, R. (1962), The Emotions: Facts, Theories, and a New Model, Random House, New York, NY.

Ramaseshan, B. and Robyn Ouschan (2017), "Investigating Status Demotion in Hierarchical Loyalty Programs," Journal of Services Marketing, 31(6), 650-61.

Ramaseshan, B., Alisha Stein, and Fazlul K. Rabbanee (2016), "Status Demotion in Hierarchical Loyalty Programs: Effects of Payment Source," Service Industries Journal, 36(9-10), 375-95.

Reed, Dan (2005), "Some Fliers Fly Extra to Keep Elite Status," USA Today, (December 27), 1B.

Ridgeway, Cecilia L. and Henry A. Walker (1995), "Status Structures," in Sociological Perspectives on Social Psychology, Karen S. Cook, Gary A. Fine, and James S. House, eds. MA: Allyn \& Bacon, 281-310. Roschk, Holger, Jena Müller, and Katja Gelbrich (2013), “Age Matters: How Developmental Stages of Adulthood Affect Customer Reaction to Complaint Handling Efforts," Journal of Retailing and Consumer Services, 20, 154-64.

Roseman, Ira J. (1984), "Cognitive Determinants of Emotions: A Structural Theory," in Shaver, P. (Ed.), Review of Personality and Social Psychology (Vol. 5), Sage, Berkeley, CA, 11-36.

Rosenbaum, Paul R. and Donald B. Rubin (1983), "The Central Role of the Propensity Score in Observational Studies for Causal Effects," Biometrika, 70(1), 41-55.

Rosenbaum, Paul R. and Donald B. Rubin (1984), "Reducing Bias in Observational Studies Using Subclassification on the Propensity Score," Journal of the American Statistical Association, 79(387), 516-24.

Shin, Jiwoong, K. Sundhir, and Dae-Hee Yoon (2012), "When to 'Fire' Customers: Customer Cost-based Pricing," Management Science, 58(5), 932-47.

Stauss, Bernd, Maxie Schmidt, and Andreas Schoeler (2005), "Customer Frustration in Loyalty Programs," International Journal of Service Industry Management, 16(3), 229-52.

Steinhoff, Lena and Robert W. Palmatier (2016), "Understanding Loyalty Program Effectiveness: Managing Target and 
Bystander Effects," Journal of the Academy of Marketing Science, 44(1), 88-107. Stellin, Susan (2009), "Sweet-Talking Top Fliers Again," The New York Times, (August 25). van Berlo, Geert, Josée Bloemer and Vera Blazevic (2014), "Customer Demotion in Hierarchical Loyalty Programmes," Service Industries Journal, 34(11), 922-37.

Wagenheim, Florian v. and Tomás Bayón (2007), "Behavioral Consequences of Overbooking Service Capacity," Journal of Marketing, 71(October), 36-47.

Wagner, Tillmann, Thorsten Hennig-Thurau, and Thomas Rudolph (2009), "Does Customer Demotion Jeopardize Loyalty?" Journal of Marketing, 73(May), 69-85.
Wang, Yanwen, Michael Lewis, Cynthia Cryder, and Jim Sprigg (2016), "Enduring Effects of Goal Achievement and Failure Within Customer Loyalty Programs: A Large-Scale Field Experiment," Marketing Science, 35 (4), 565-75.

Yamanouchi, Kelly (2009), “Frequent Fliers May Lose Perks: Delta, AirTran Will Shorten Expiration, Flexibility of Points," The Atlanta Journal-Constitution, (January 20), 1B.

Zeithaml, Valarie A., Roland T. Rust, and Katherine N. Lemon (2001), "The Customer Pyramid: Creating and Serving Profitable Customers," California Management Review, 43(4), 118-42. 


\section{〈Appendix〉}

Percentage Reduction in Bias (PRB)

$P R B_{n}=1-\left|\frac{\bar{x}_{i, n}^{A}-\bar{x}_{j, n}^{A}}{\bar{x}_{i, n}^{B}-\bar{x}_{j, n}^{B}}\right|$

Where

$P R B_{n}=$ the percentage reduction in bias for the nth predictor variable,

$\bar{x}_{i, n}^{A} \quad=$ the mean of the nth predictor variable for the treatment group after matching,

$\bar{x}_{j, n}^{A} \quad=$ the mean of the nth predictor variable for the nontreatment group after matching,

$\bar{x}_{i, n}^{B} \quad=$ the mean of the nth predictor variable for the treatment group before matching,

$\bar{x}_{j, n}^{B} \quad=$ the mean of the nth predictor variable for the nontreatment group before matching, and

$N \quad=$ the number of predictor variables. 